\title{
Short range dispersal of western flower thrips in field-grown French beans in Kenya
}

\section{Johnson O. Nyasani ${ }^{1,2 *}$, Sevgan Subramanian ${ }^{2}$, Benedict Orindi ${ }^{2}$, Hans-Michael Poehling ${ }^{3}$ and Rainer Meyhöfer ${ }^{3}$}

\author{
${ }^{1}$ Department of Crop Protection, Kenya Agricultural and Livestock Research \\ Organization-Embu, PO Box 27-60100, Embu, Kenya; ${ }^{2}$ Plant Health Division, \\ International Centre of Insect Physiology and Ecology, PO Box 30772-00100, \\ Nairobi, Kenya; ${ }^{3}$ Section Phytomedicine, Institute of Horticultural Production \\ Systems, Leibniz Universität Hannover, Herrenhäuser Strasse 2, 30419 Hannover, \\ Germany
}

(Accepted 8 August 2016)

\begin{abstract}
The short-range diurnal dispersal pattern of adult western flower thrips Frankliniella occidentalis (Pergande), in relation to spatial distribution of French beans, was determined in the field. A total of 1200 adult female F. occidentalis were released on 60 French bean plants with 20 adult thrips per plant at the central release point of $3.14 \mathrm{~m}^{2}$. Dispersal was determined in terms of the number of thrips recorded on French beans planted on concentric circles at $0.9,1.8,3.6,7.2$ and $14.4 \mathrm{~m}$ radii from a circular central release point for five days. Results indicated that there was a steady increase in the proportion of dispersing adult $F$. occidentalis from the first to the fourth day in the first planting season, and from the first to the third day in the second planting season. The peak hour for dispersal was $10.15 \mathrm{~h}$ in the first season while it was $13.15 \mathrm{~h}$ in the second season. Temperature and wind speed were positively associated with the dispersal activity of adult $F$. occidentalis. Minimal flight activity was at temperatures below $15{ }^{\circ} \mathrm{C}$ and peak flight activity was at $19{ }^{\circ} \mathrm{C}$. The prevailing wind direction did not influence the dispersal pattern of adult F. occidentalis in both seasons. Adult F. occidentalis moved up to $7.2 \mathrm{~m}$ on French beans on the first day. In both seasons, the mean direction of thrips dispersal was mostly uniformly distributed (not oriented to a particular compass direction) around the central release point. The results provide an insight into developing integrated management strategies against the pest based on isolation of farm fields, management of alterative hosts around French bean fields and insecticide application.
\end{abstract}

Key words: colonization, Frankliniella occidentalis, Phaseolus vulgaris, circular statistics

\section{Introduction}

The western flower thrips Frankliniella occidentalis (Pergande) (Thysanoptera: Thripidae) is a major worldwide pest of ornamental and horticultural crops (Kirk, 2002). The species causes considerable damage to a wide range of plants through feeding, oviposition and transmission of tospoviruses (Kirk and Terry, 2003). In Kenya, for instance, F. occidentalis

*E-mail: jnyasani@icipe.org is an important pest of French bean, Phaseolus vulgaris L. (Fabaceae) (Nderitu et al., 2009; Nyasani et al., 2012, 2013a,b). Adult F. occidentalis are small (1-2 $\mathrm{mm}$ in length), and have slender wings fringed with cilia with both males and females being capable of flight (Lewis, 1997). For dispersal, adult thrips take off by simultaneously flexing their abdomen, flapping their wings and jumping with their hind legs (Lewis, 1997). Their patterns of flight behaviour have not been as widely studied as that of other insects, such as aphids or locusts (Pearsall, 2002). 
Since adult $F$. occidentalis have a limited dispersal capacity, they often colonize the first (nearest) plant they encounter (Rhainds and Shipp, 2004). It is believed that previous colonization of host plants by conspecifics enhances the incidence of adult dispersal (Agrawal and Colfer, 2000; Rhainds and Shipp, 2003), and dispersal may generate a relatively uniform distribution of thrips among plants (Rhainds and Shipp, 2004). For small-winged insects, such as thrips, it is reasonable to hypothesize that wind direction and intensity play a role in their movement and dispersal. However, a previous study has indicated that the mean direction of dispersal of adult F. occidentalis into orchards located adjacent to wild land was found to be primarily from these source areas, regardless of the dominant wind flow patterns (Pearsall and Myers, 2001).

Invasion of field crops by thrips is usually due to either infested nursery transplants or immigration of adults from neighbouring fields, but little information is available on how thrips populations colonize and disperse within a field crop. Knowledge about the movement pattern of thrips into, out of, and within a particular crop is important in understanding and predicting its population dynamics in space and time, and in providing information for possible sampling schemes and management strategies (Pearsall and Myers, 2001). In Kenya, land holding is small in areas of high agricultural potential that often results in French beans of a different phenology being grown adjacent $(0.5-10 \mathrm{~m})$ to one another (Kimenye, 2002). The growing of young French beans in the vicinity of old crop fields or other alternative hosts that harbour thrips poses a serious problem, as old fields may act as a 'green bridge' for carryover of thrips to the newly planted fields. Previous studies have indicated that there is a sudden influx of $F$. occidentalis to new French bean fields at flowering stage (Nyasani et al., 2013b). However, few studies have rigorously investigated the short-range dispersal pattern of adult $F$. occidentalis on field-grown crops such as French bean. Thus, the objective of the present study was to determine the short-range diurnal dispersal pattern of adult F. occidentalis in relation to the spatial distribution of French bean, to predict its relative dispersal capacity and ability to infest new fields in an agroecosystem.

\section{Materials and methods}

\section{Experimental site}

Field experiments to determine the short-range diurnal dispersal pattern of adult $F$. occidentalis on French bean were conducted at the Kenya Agricultural and Livestock Research Organization (KALRO), Embu Centre, Kenya. KALRO-Embu is located in the Upper Midlands 2 (UM2) agroecological zone at an altitude of $1480 \mathrm{~m}\left(0.501291^{\circ} \mathrm{S}\right.$, $37.458664^{\circ} \mathrm{E}$ ). It is characterized by a fairly flat and structurally good landscape. Its soils are classified as Humic Nitisols. It receives an annual rainfall of 1238 mm (Jaetzold et al., 2007). The experiments were conducted in two planting seasons: March to April and June to July 2011.

\section{Experimental design}

Empirical models assessing variations of population density as a function of the distance from a point source have been used to quantify the dispersal ranges of several insect species (Roslin, 2000; Cronin et al., 2000; Cronin et al., 2001). Additionally, since dispersal range of an organism is understood as the numerical variation in a population density due to the natural movement of its individuals over time (Ricklefs and Miller, 2000; Nathan, 2001), we used a concentric circle design as outlined by DarrouzetNardi et al. (2006) (Fig. 1) to study the dispersal pattern of adult F. occidentalis in French bean fields. The experiment was conducted at the centre of the field. To prevent infestation from the surroundings, a buffer zone of $30 \mathrm{~m}$ around the experimental fields was kept weed free before and during the experiments. The same experimental design was used in the two planting seasons: March to April and June to July 2011. The experiment was replicated twice in each season.

\section{Crop}

A total of 60 French bean plants Phaseolus vulgaris L. (cv Serengeti) were planted on a flat bed in an open field at the central release point of $3.14 \mathrm{~m}^{2}$ to simulate a 'source' plot for thrips infestation (Fig. 1). To determine the dispersal pattern of adult $F$. occidentalis from the central release point, French beans were also planted at a spacing of $15 \mathrm{~cm}$ between plants on concentric circles of $0.9,1.8,3.6,7.2$ and $14.4 \mathrm{~m}$ radii from the 'source' plot (Fig. 1). The distances (radii) from the central release point were chosen based on the real farmer situations as observed during the survey studies on the seasonality of F. occidentalis on French bean under farmers' fields (Nyasani et al., 2013b). At planting, diammonium phosphate (DAP) fertilizer was applied at the rate of $10 \mathrm{~g}$ per hole and mixed well with the soil. Two French bean seeds were planted per hole and later thinned to one per hole. A total of 38, 75, 150, 300 and 600 plants were planted at $0.9,1.8,3.6,7.2$ and $14.4 \mathrm{~m}$ radii, respectively. The buffer zones between concentric circles and the surroundings of the experimental fields ( $30 \mathrm{~m}$ all round) were kept weed free before and during the experiments to prevent 


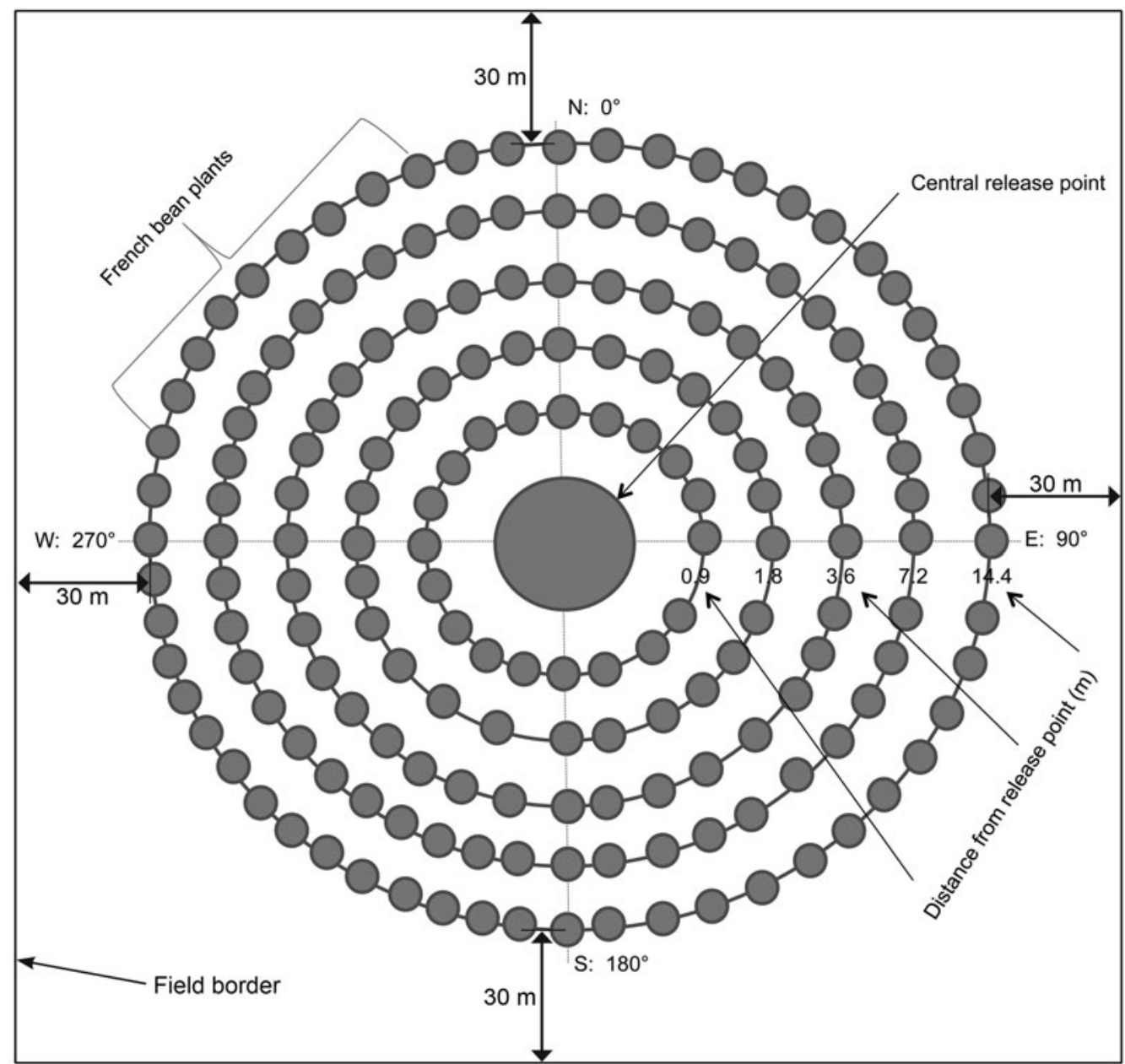

Fig. 1. Experimental design to determine the dispersal pattern of adult western flower thrips (WFT) Frankliniella occidentalis. The solid circle at the centre represents the point where 1200 adult WFT were released, and the smaller circles represent the French bean plants planted in different concentric circles depicting various radii from the release point.

infestation from the surroundings. No fungicide, foliar feed or insecticide was applied on the French bean plants during the entire experimental period. Cultural practices as recommended by the Ministry of Agriculture were adopted (Jaetzold et al., 2007).

\section{Experimental insects}

Initial cultures of $F$. occidentalis were field collected from French beans at Thika, Kenya, in January 2011. Sample specimens were further processed in the laboratory to confirm identity of the thrips using LucID key (Moritz et al., 2004). The F. occidentalis were reared in ventilated plastic jars $(9 \mathrm{~cm} \times 15 \mathrm{~cm} \times$ $8 \mathrm{~cm}$ ). A hole was cut on the lid and covered with thrips-proof organdy cloth (mesh openings of 95 $\mu \mathrm{m})$ to allow ventilation. The thrips were reared at the International Centre of Insect Physiology and Ecology (icipe)'s insectary at $25 \pm 1{ }^{\circ} \mathrm{C}, 50$
$60 \%$ relative humidity $(\mathrm{RH})$ with a $12 \mathrm{~h} \mathrm{~L}: 12 \mathrm{~h} \mathrm{D}$ photoperiod as described by Nyasani et al. (2013a). French bean pods, surface coated with sugar and honey solution, were used as a food supplement. To determine the sex of newly hatched thrips ( 2 days old), 5 thrips were placed in a $6 \mathrm{~cm}$ diameter Petri dish and classified under a stereomicroscope based on external morphological differences. Adult female and male $F$. occidentalis were aspirated separately and transferred into individual ventilated plastic jars.

We only used adult females, since sex ratios of F. occidentalis from field samples are often biased towards one sex (Reitz, 2009). Furthermore, it is the females that pose the greatest challenge, because they are responsible for reproduction, both asexually and sexually, hence perpetuating their population density. At the six leaf stage, baseline sampling for thrips on the French bean plants was 
done and no thrips were observed on the plants in both planting seasons. Newly hatched (3 days old) adult female F. occidentalis were subsequently released onto the middle leaves of French beans using a modified straw with 20 thrips per plant and left to acclimatize for two hours before the start of data collection. All the 60 French bean plants at the central release point were infested with F. occidentalis. The releases were made at 06:00 h when thrips are known to be inactive and at the six leaf stage to avoid attraction of thrips into flowers, thus limiting dispersal.

\section{Sampling and quantifying thrips movement}

Two hours after release, approximately $10 \%$ of the plants in each concentric ring up to a maximum of 20 plants (i.e. 5, 10, 15, 20 and 20 French bean plants at $0.9,1.8,3.6,7.2$ and $14.4 \mathrm{~m}$ radii, respectively) were observed for thrips colonization every hour during the day for five days. At each field observation, the plants sampled for thrips were tagged to allow other plants to be sampled in the next field observation. The thrips detected on the French bean plants were carefully collected using a fine bristle brush and placed in plastic vials containing $70 \%$ ethyl alcohol. The thrips specimens were further processed in the laboratory and identified to species level using the LucID key (Moritz et al., 2004; Moritz et al., 2013). During the field observations, plants at the central release point were not observed for thrips infestation so as not to influence dispersal of thrips to neighbouring plants. However, at the end of the experiment, the number of thrips observed on all the 60 French bean plants at the central release point were counted and recorded.

Upon identification, $100 \%$ of the thrips collected were F. occidentalis. Voucher specimens of slidemounted thrips from this study are maintained in the thrips IPM programme lab at icipe, Nairobi, Kenya. Dispersal of adult F. occidentalis was measured by the number of thrips recorded on French bean at each concentric circle. The prevailing daily weather conditions (rainfall, $\mathrm{RH}$, wind and temperature) were recorded at a neighbouring weather station (150 m away) at KALRO, Embu.

\section{Data analysis}

All circular data were first transformed into radians before analyses. The analyses were performed using R v2.13.1 (R Development Core Team, 2010). The circular statistics were obtained using the CirStats package (Claudio, 2009) as described by Jammalamadaka and SenGupta (2001). The results on a circular scale were presented using 'rose' diagrams, which depict frequencies (as the area of the wedge) and dispersion of the measured angle
(Wells, 2000). The rose diagrams were constructed using Oriana v4 (Kovach, 2011).

The sample mean resultant length ( $\mathrm{r}$ - rho) and the angular deviation (s) characterized thrips dispersal such that the angular variance $s^{2}$ was as defined by Batschelet (1981). The measure of concentration was given by the value $\rho$, which varies from 0 (when there is so much dispersion that a mean angle cannot be described) to 1 (when all the data are concentrated at the same direction). Directionality in the distribution of adult F. occidentalis at each radius and day was tested for significance using the Rayleigh test (Batschelet, 1981). Rao's test for homogeneity was used to compare the distribution of thrips (i.e. to test for differences in mean directions and/or differences in concentrations at different radii/distances from the release point) (Rao, 1967).

A circular-linear correlation was used to determine the correlation between prevailing weather parameters (wind speed and temperature) and the dispersal activity of adult $F$. occidentalis (daily catches). The correlation analyses were performed using Oriana v4 (Kovach, 2011). Rainfall and RH were not included in the correlation analysis, because there were only two rainfall events in both planting periods. Wind direction was computed in terms of degrees. To understand the influence of wind direction on thrips captures, the numbers of adult F. occidentalis recorded at each sampling point corresponding with the prevailing wind direction were subjected to ANOVA using package circular statistics in Oriana v4. All tests were performed at the $5 \%$ significance level.

\section{Results}

\section{Differences in the number of thrips dispersing by distance and time}

The recapture rate of adult $F$. occidentalis in the first season was $93.7 \%$ and $35.1 \%$ in the second season. At the end of the experiment (five days after thrips release), $3.6 \%$ of adult $F$. occidentalis remained at the central release point in the first season, while $46.8 \%$ of the thrips remained at the central release point in the second planting season. In the first season, there was a steady increase in the proportion of dispersing adult F. occidentalis from the first to the fourth day, and this remained constant thereafter (Fig. 2). In the second season, there was a slight increase in the proportion of dispersing adult $F$. occidentalis from the first to the third day and from the fourth to the fifth day. A decline in the proportion of dispersing adult $F$. occidentalis was seen on the fourth day (Fig. 2).

The results indicate that the peak hour for dispersal was at 10:15 $\mathrm{h}$ in the first season while it 


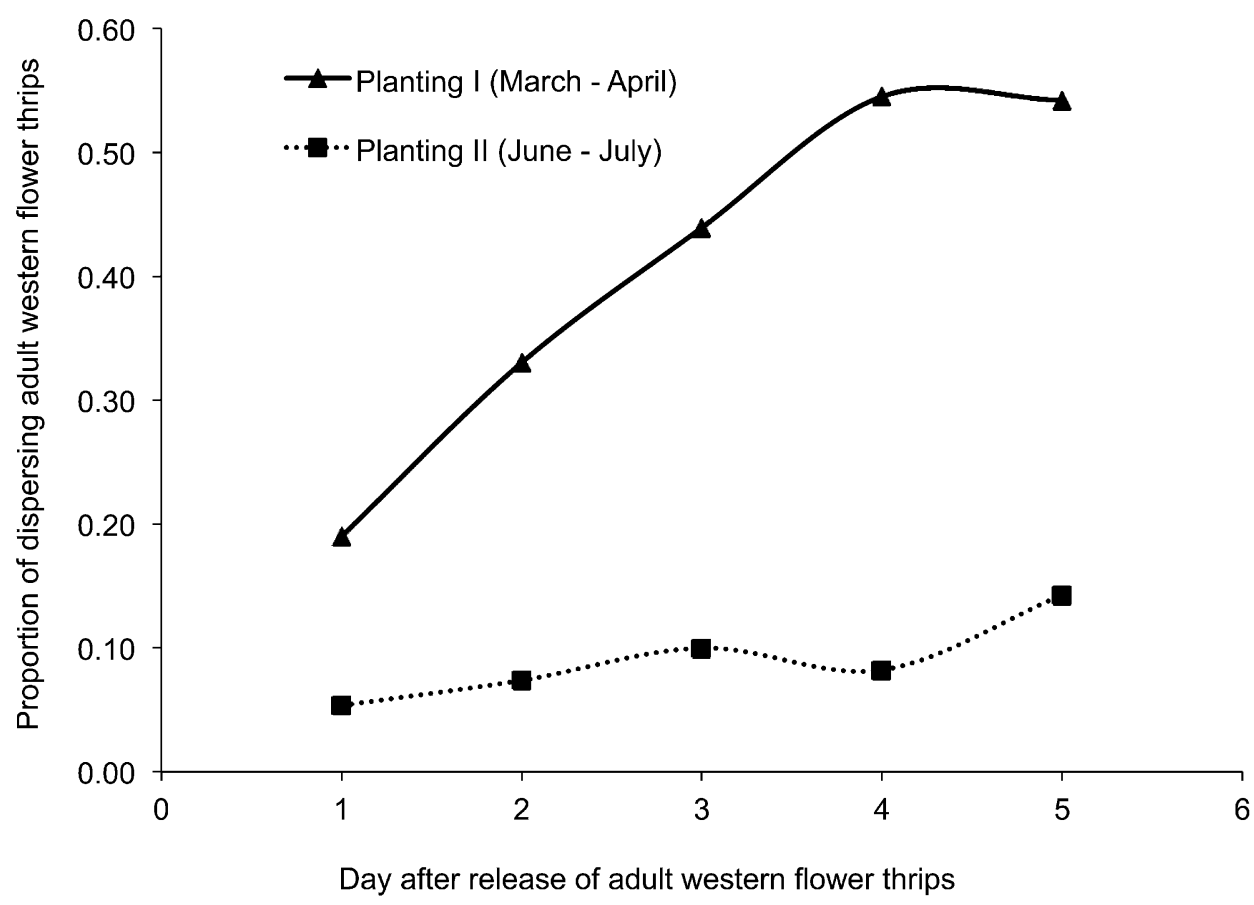

Fig. 2. Cumulative proportion of dispersing adult western flower thrips (WFT) Frankliniella occidentalis on French beans five days after release of 1200 adult WFT at the central release point in experimental fields.

was 13:15 $\mathrm{h}$ in the second season (Fig. 3). The peak period for dispersal mainly depended on prevailing weather conditions. Temperature and wind speed were positively correlated with the dispersal activity of adult $F$. occidentalis $(\mathrm{r}=0.711$, d.f. $=8, P=0.021$ and $\mathrm{r}=0.548$, d.f. $=8, P=0.030$, respectively). It was observed that flight was minimal at temperatures below $15{ }^{\circ} \mathrm{C}$, whereas the peak flight activity was at $19{ }^{\circ} \mathrm{C}$ (Fig. 3). In the first season, the number of adult $F$. occidentalis catches remained unchanged at temperatures of $21-24{ }^{\circ} \mathrm{C}$ (Fig. 3). In the second season, the numbers of adult $F$. occidentalis catches recovered on French bean were relatively lower compared with those in the first planting season (Fig. 3). Adult F. occidentalis were only able to disperse from the central release point up to $7.2 \mathrm{~m}$ on the first day and no thrips were observed on French bean at 14.4.m from the central release point on the first day (Fig. 4) in both planting seasons. The peak period for dispersal was on the third day after release of adult $F$. occidentalis (Fig. 4). On the third day (peak period for dispersal), the least number of adult $F$. occidentalis per plant $(3.9 \pm 0.7)$ was recorded at $0.9 \mathrm{~m}$ while the numbers of adult F. occidentalis per plant recorded at 1.8, 3.6, 7.2 and $14.4 \mathrm{~m}$ were $1.9,3.2,3.7$ and 2.4 times higher than those at $0.9 \mathrm{~m}$, respectively (Fig. 4). A decline in the density of dispersing adult F. occidentalis was observed from the third to the fifth day for all distances (Fig. 4).

\section{Dispersal direction of adult western flower thrips}

In the first planting season the prevailing wind direction did not influence the dispersal pattern of adult $F$. occidentalis $\left(\mathrm{F}_{6,17}=1.664, P=0.191\right)$ and mean direction of dispersal for adult $F$. occidentalis varied among the five days. Out of the five days, the mean direction of thrips dispersal was uniformly distributed (not oriented to a particular compass direction) around the central release point on the first, third, fourth, and fifth days $\left(\overline{\mathrm{a}}=193.0^{\circ}, \mathrm{r}=\right.$ $0.044, P=0.632 ; \overline{\mathrm{a}}=252.7^{\circ}, \mathrm{r}=0.033, P=0.718 ; \overline{\mathrm{a}}=$ $267.3^{\circ}, \mathrm{r}=0.112, P=0.080$; and $\overline{\mathrm{a}}=80.5^{\circ}, \mathrm{r}=0.954$, $P=0.768$, respectively) (Fig. 5). The only exception was on the second day, where adult $F$. occidentalis were oriented (non-uniformly distributed) towards the NW direction $\left(\overline{\mathrm{a}}=279.1^{\circ}, \mathrm{r}=0.112, P=0.017\right)$ (Fig. 5).

In the second planting season, the prevailing wind direction did not influence the dispersal pattern of adult $F$. occidentalis $\left(\mathrm{F}_{7,16}=0.765, P=\right.$ $0.624)$. Similar to the first planting season, the mean direction of dispersal for adult $F$. occidentalis varied among the five days. Adult F. occidentalis were uniformly distributed around the central release point on the second and fourth days $\left(\overline{\mathrm{a}}=224.4^{0}\right.$, $\mathrm{r}=0.157, P=0.147$; and $\overline{\mathrm{a}}=262.2^{0}, \mathrm{r}=0.183$, $P=0.085)$. Conversely, the mean direction of thrips dispersal was non-uniformly distributed around the central release point on the first, third and fifth 


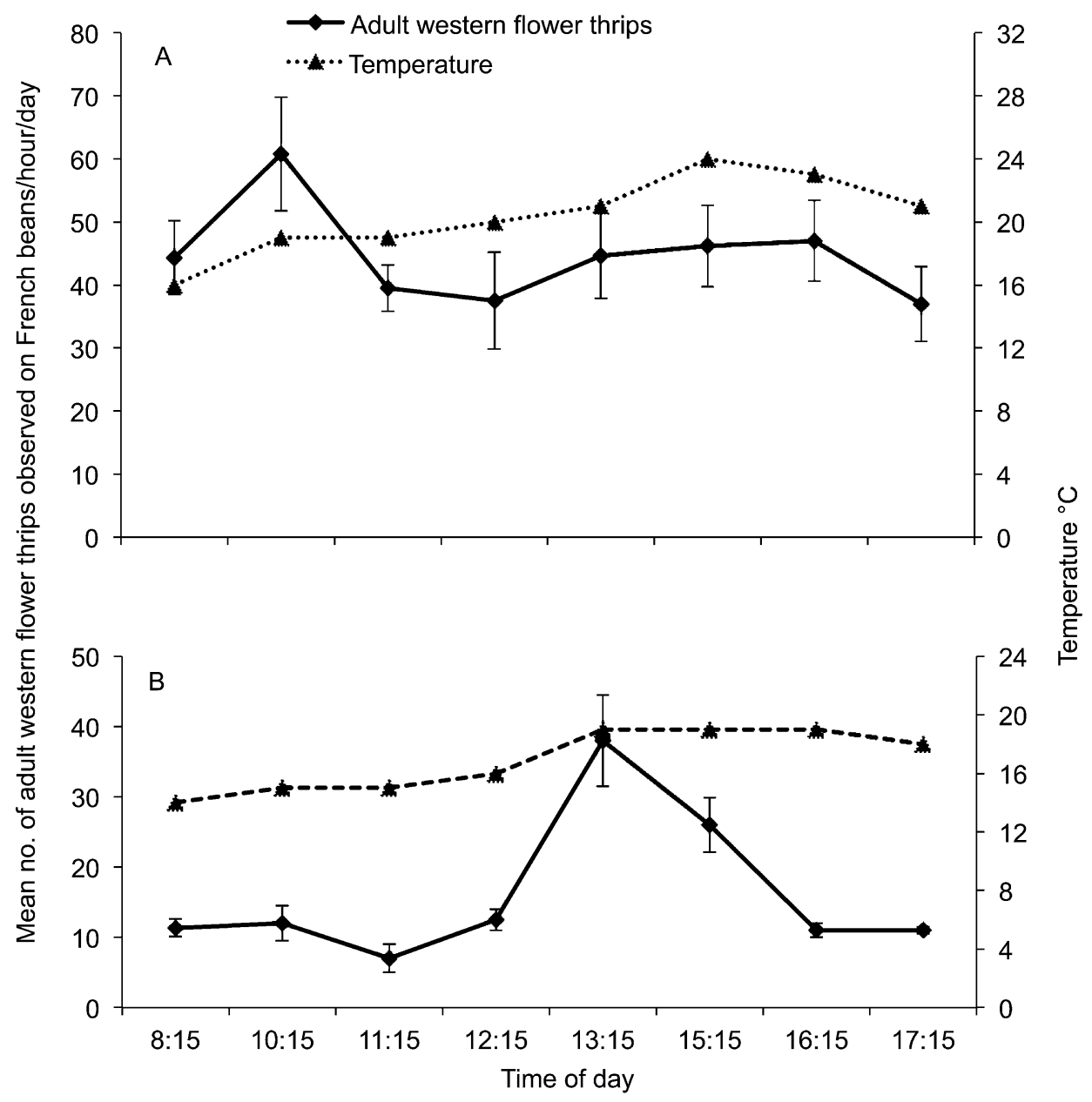

Fig. 3. Hourly patterns of flight of adult western flower thrips (WFT) Frankliniella occidentalis on French beans at KALROEmbu in: (A) March-April and (B) June-July 2011. Mean number ( \pm SEM) of adult WFT per hour per day was calculated from total hourly catches after release of 1200 adult WFT at the centre of experimental fields.

days $\left(\overline{\mathrm{a}}=224.0^{0}, \mathrm{r}=0.315, P=0.001 ; \overline{\mathrm{a}}=265.1^{0}\right.$, $\mathrm{r}=0.312, P<0.001$; and $\overline{\mathrm{a}}=261.8^{0}, \mathrm{r}=0.293$, $P<0.001$, respectively) (Fig. 5). In general, mean direction of thrips dispersal varied among the five days and between planting seasons, suggesting that other factors other than the major wind flow were responsible for the direction of dispersal for the thrips.

\section{Discussion}

Adult F. occidentalis were only capable of colonizing French bean grown at 0.9, 1.8, 3.6 and $7.2 \mathrm{~m}$ on the first day after release. However, dispersal increased over time and adult F. occidentalis were able to colonize French bean plants grown at $14.4 \mathrm{~m}$ from the central release point. This indicates that French bean grown closer to the release point (source) is likely to receive the highest adult F. occidentalis infestation rates and can serve as a 'green bridge' for infestation of French bean at longer distances from the 'source' field. Previous studies on dispersal of adult F. occidentalis in greenhouse crops have shown that the thrips have a limited dispersal capacity on cucumber ( $\mathrm{Cu}$ cumis sativus L. (Cucurbitaceae)) or chrysanthemum (Dendranthema grandiflora (Tzelev) (Asteraceae)), and often colonize the first (nearest) plants they encounter (Rhainds and Shipp, 2004). Our results also support those of Kareiva (1982) working on the dispersal pattern of two crucifer-feeding flea beetles, Phyllotreta cruciferae and Phyllotreta striolata under field conditions and Rhainds and Shipp (2004) working on the dispersal pattern of adult F. occidentalis in greenhouse crops, who reported that over time insect dispersal can happen over a relatively wide spatial scale with each adjacent 


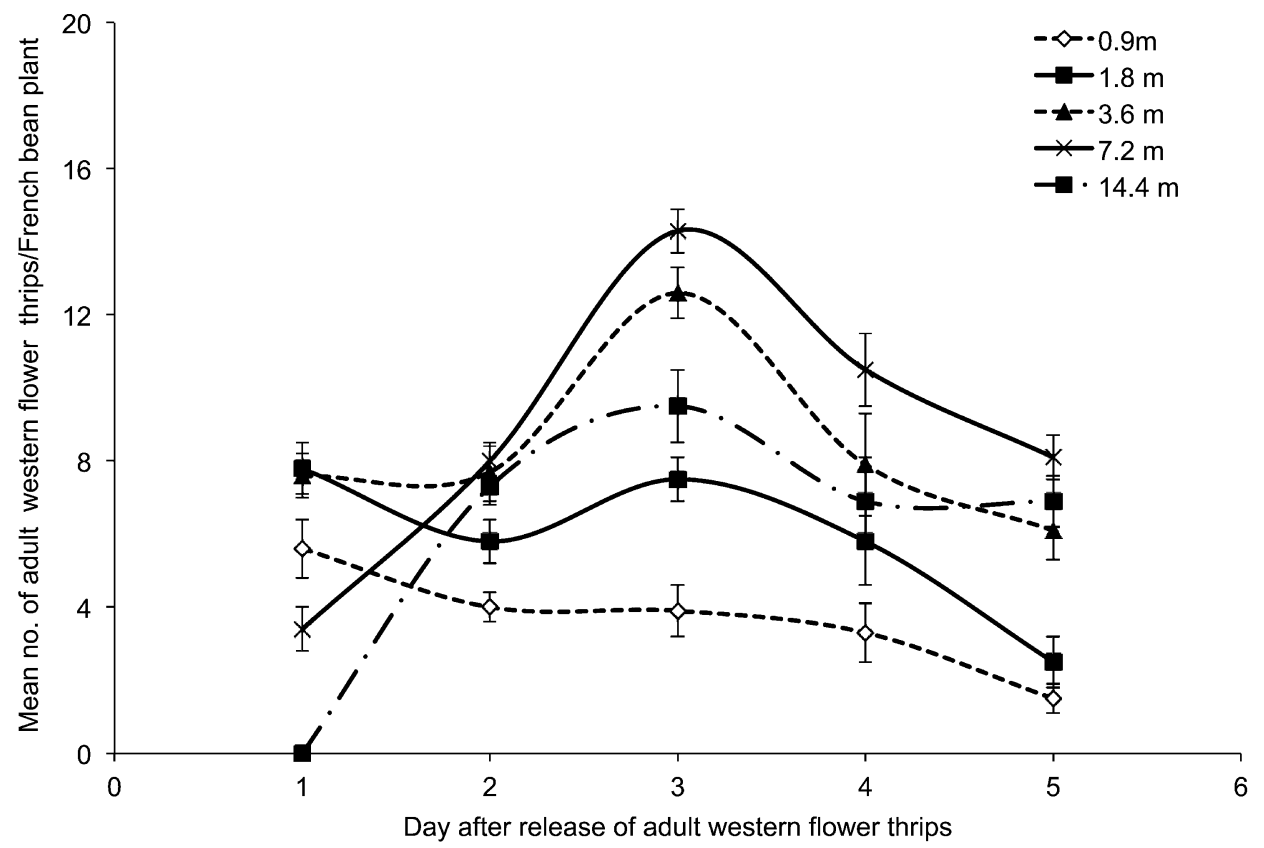

Fig. 4. Mean number $( \pm$ SEM) of adult western flower thrips (WFT) Frankliniella occidentalis recorded per French bean plant at different distances (radii) from the central release point for five days. A total of 1200 adult WFT were released at the centre of the experimental fields and their movement monitored for five days.
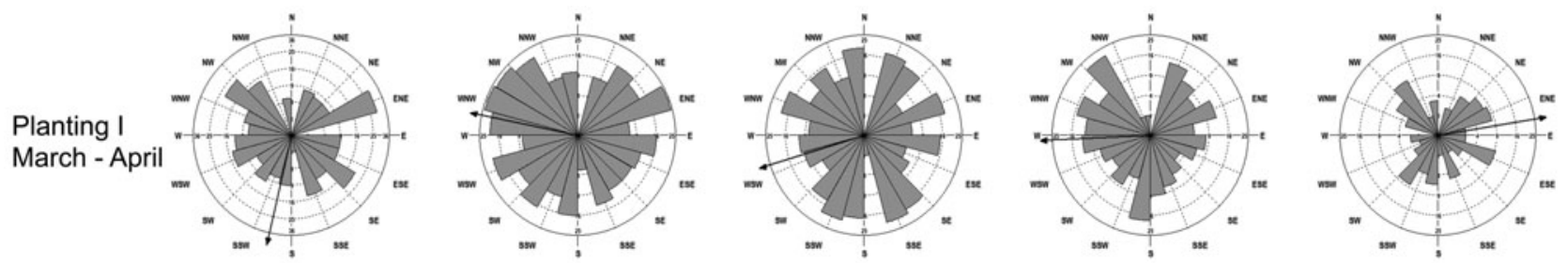

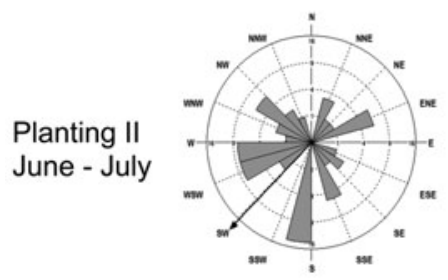

Day 1

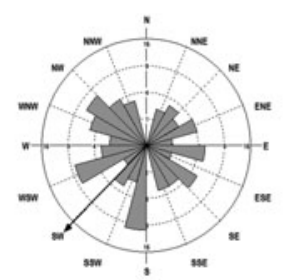

Day 2

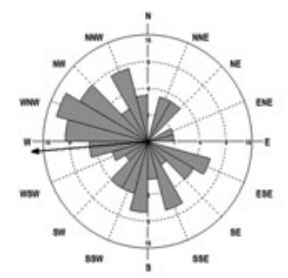

Day 3

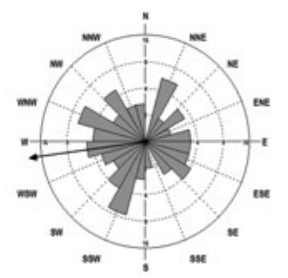

Day 4

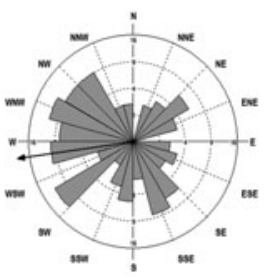

Day 5

Fig. 5. Daily dispersal patterns of adult western flower thrips (WFT) Frankliniella occidentalis on field-grown French beans at KALRO-Embu, Kenya in March-April and June-July 2011. The bigger the wedge of the 'rose' diagram, the bigger the number of adult WFT recorded at that angle. An arrow pointing outwards shows the daily mean flight direction. The significance of the mean direction of flight of WFT on each day was tested by Rayleigh test at $P<0.05$.

host plant potentially acting as a stepping stone. The results have implications on management of F. occidentalis on French bean in terms of isolating old fields from new ones, managing alternative hosts within French bean fields, applying insecticide, and devising crop rotation schemes.
Dispersal of adult F. occidentalis was at the peak at 10:15 $\mathrm{h}$ and 13:15 $\mathrm{h}$ in the first and second planting seasons, respectively. Our results corroborate those of Kasina et al. (2006), who reported that dispersal of adult F. occidentalis on field-grown French bean was at peak at 10:00-13:00 h. Dispersal of adult 
J.O. Nyasani et al.

F. occidentalis was dependent on temperature with minimal dispersal activity at temperatures below $15{ }^{\circ} \mathrm{C}$ and maximum activity at $19{ }^{\circ} \mathrm{C}$. However, at temperatures of $21-24{ }^{\circ} \mathrm{C}$, there was a decline in dispersal activity of adult F. occidentalis in the first planting season. Our results are in agreement with those of Pearsall (2002), who reported that the dispersal activity of adult $F$. occidentalis on nectarine orchards was rare at $15{ }^{\circ} \mathrm{C}$ and most common between 15 and $30{ }^{\circ} \mathrm{C}$. Similarly, temperature has been reported as the major environmental factor that affects thrips dispersal (Pearsall and Myers, 2001; Morsello et al., 2008; Morsello et al., 2010). It has been reported that once temperature increases above the flight threshold (c. $\left.17-21^{\circ} \mathrm{C}\right)$, thrips dispersal may occur en masse (Lewis, 1997; Morsello et al., 2008). In our study, wind speed was positively correlated with dispersal activity of $F$. occidentalis. According to Lewis (1973) and Pearsall and Myers (2001), it is unlikely for thrips to direct their direction of flight at higher wind speeds, because they can be blown upwards and away from their breeding or overwintering sites, hence increasing their dispersal distance.

In the first and second planting seasons, F. occidentalis were mostly uniform (not oriented to a particular compass direction) around the central release point. The results indicate that dispersal of adult F. occidentalis is mainly uniform and therefore, the density of thrips among French bean plants within a limited spatial scale may be uniform, due to between and within plant dispersal. The lack of orientation of adult $F$. occidentalis towards a particular compass direction might be because of the wind forming eddies around the thrips; thus the thrips originating from one direction may be thrust to another direction on French bean. It is also believed that thrips are unable to direct the course of their flight (Pearsall and Myers, 2001); however, it is possible that they may be able to control their direction at very low wind speeds (Pearsall and Myers, 2001). Nevertheless, directed movements in response to olfactory and visual stimuli can modify distribution patterns of insects (Pasek, 1988). Our results support those of Pearsall and Myers (2001) and Rhainds et al. (2005), who reported uniform distribution of adult $F$. occidentalis in nectarine orchards and Chrysanthemum, respectively.

The daily dispersal activity of adult $F$. occidentalis on French bean was lower on the first, second, fourth and fifth days, whereas the daily dispersal activity was higher on the third day. The lower dispersal activity of $F$. occidentalis on the first day might have been because lab-reared adult F. occidentalis released on French bean were acclimatizing to the new environment. The lower catches of F. occidentalis recorded on the fifth day were due to the high capture rates recorded on the third day. Additionally, the population at source was reducing over time and the willingness of the thrips to disperse might have been reduced.

Our results suggest that dispersal pattern of adult F. occidentalis on French bean is mainly not oriented towards a specific compass direction. We also show that adult $F$. occidentalis are capable of dispersing up to $7.2 \mathrm{~m}$ on French bean in a day. An understanding of the dispersal pattern of adult $F$. occidentalis is important in developing sustainable management options against the pest based on the isolation of farm fields in a rotation scheme and management of alternative hosts within French bean fields. To extrapolate the results to a wider scale, further studies are recommended to understand the role of landscape features, cropping patterns, weather conditions, and pest management strategies on dispersal of adult F. occidentalis.

\section{Acknowledgements}

The authors thank Bernard Mulwa for technical assistance. We thank the Director, KALRO-Embu, Kenya for allowing us to carry out the studies at the Centre. We gratefully thank the icipe, Nairobi, Kenya for providing logistical support during data collection, analysis and reporting. We gratefully acknowledge the financial support for this research by the following organizations and agencies: Federal Ministry for Economic Cooperation and Development, Germany (BMZ) and Deutsche Gesellschaft für Internationale Zusammenarbeit (GIZ), Grant number 07.7860.5-001.00, and icipe core funding from UK Aid from the UK Government, Swedish International Development Cooperation Agency (Sida), the Swiss Agency for Development and Cooperation (SDC), Federal Ministry for Economic Cooperation and Development (BMZ), Germany and the Kenyan Government. The views expressed herein do not necessarily reflect the official opinion of the donors.

\section{References}

Agrawal A. A. and Colfer R. G. (2000) Consequences of thrips-infested plants for attraction of conspecifics and parasitoids. Ecological Entomology 25, 493-496.

Batschelet E. (1981) Circular Statistics in Biology. Academic Press, London/NewYork. 371 pp.

Claudio A. (2009) CircStats: Circular Statistics, from "Topics in circular Statistics" (2001). R package version 0.24. Available at: http://CRAN.R-project.org/package= CircStats. 
Cronin J. T., Hyland K. and Abrahamson W. G. (2001) The pattern, rate, and range of within-patch movement of a stem-galling fly. Ecological Entomology 26, 16-24. doi:10.1046/j.1365-2311.2001.00294.x.

Cronin J. T., Reeve J. D., Wilkens R. and Turchin P. (2000) The pattern and range of movement of a checkered beetle predator relative to its bark beetle prey. Oikos 90, 127-138. doi:10.1034/j.1600-0706.2000. 900113.x.

Darrouzet-Nardi A., Hoopes M. F., Walker J. D. and Briggs C. J. (2006) Dispersal and foraging behaviour of Platygaster californica: hosts can't run, but they can hide. Ecological Entomology 31, 298-306. doi:10.1111/j.13652311.2006.00798.x.

Jaetzold R., Schmidt H., Hornetz B. and Shisanya C. (2007) Farm Management Handbook of Kenya Vol. II. Natural Conditions and Farm Management Information. Part C East Kenya. Subpart C1 Eastern Province. Ministry of Agriculture, Nairobi, Kenya. 411 pp.

Jammalamadaka S. R. and SenGupta A. (2001) Topics in circular statistics, pp. 336. In Series on Multivariate Analysis Vol 5 (edited by M. M. Rao). World Scientific Press, Singapore/New Jersey/London/Hong Kong.

Kareiva P. (1982) Experimental and mathematical analyses of herbivore movement: quantifying the influence of plant spacing and quality on foraging discrimination. Ecological Monographs 52, 261282.

Kasina J., Nderitu J., Nyamasyo G., Olubayo F., Waturu C., Obudho E. and Yobera D. (2006) Diurnal population trends of Megalurothrips sjostedti and Frankliniella occidentalis (Thysanoptera: Thripidae) and their natural enemies on French bean Phaseolus vulgaris (Fabaceae). International Journal of Tropical Insect Science 26, 2-7. doi: $10.1079 /$ IJT2006101.

Kimenye L. N. (2002) Promoting farm/non-farm linkages: a case study of French bean processing in Kenya, pp. 145-170. In Promoting Farm/non-farm Linkages for Rural Development: Case Studies from Africa and Latin America (edited by B. Davis, T. Reardon, K. Stamoulis and P. Winters). Food and Agriculture Organization of the United Nations, Rome, Italy.

Kirk W. D. J. (2002) The pest and vector from the west: Frankliniella occidentalis, pp. 33-44. In Thrips and Tospoviruses: Proceedings of the 7th International Symposium on Thysanoptera (edited by R. Marullo and L. A. Mound). Australian National Insect Collection, Canberra, Australia.

Kirk W. D. J. and Terry L. I. (2003) The spread of the western flower thrips Frankliniella occidentalis (Pergande). Agricultural and Forest Entomology 5, 301-310. doi:10.1046/j.1461-9563.2003.00192.x

Kovach W. L. (2011) Oriana-Circular Statistics for Windows, ver. 4. Kovach Computing Services, Pentraeth, Wales, UK. 175 pp.

Lewis T. (1973) Thrips: Their Biology, Ecology and Economic Importance. Academic Press, London/New York. 349 pp.
Lewis T. (1997) Flight and dispersal, pp. 175-196. In Thrips as Crop Pests (edited by T. Lewis). CAB, Oxon, United Kingdom.

Moritz G., Brandt S., Triapitsyn S. and Subramanian S. (2013) Identification and Information Tools for Pest Thrips in East Africa. QBIT, QAAFI, UQ. Available at: http: / / thripsnet.zoologie.uni-halle.de/key-serverneu/data/03030c05-030b-4107-880b-0a0a0702060d/ media/Html/index.html.

Moritz G., Mound L. A., Morris D. C. and Goldarazena A. (2004) Pest Thrips of the World on CD-ROM. An Identification and Information System using Molecular and Microscopical Methods. Centre for Pest Information Technology and Transfer, The University of Queensland, Brisbane. Available at: http: / thripsnet.zoologie.uni-halle.de/key-serverneu/data/09070302-040a-4006-8c08-0e0105060801/ media/Html/index.html.

Morsello S. C., Beaudoin A. L. P., Groves R. L., Nault B.A. and Kennedy G. G. (2010) The influence of temperature and precipitation on spring dispersal of Frankliniella fusca changes as the season progresses. Entomologia Experimentalis et Applicata 134, 260-271. doi:10.1111/j.1570-7458.2009.00959.x.

Morsello S. C., Groves R.L., Nault B. A. and Kennedy G. G. (2008) Temperature and precipitation affect seasonal patterns of dispersing tobacco thrips, Frankliniella fusca, and onion thrips, Thrips tabaci (Thysanoptera: Thripidae) caught on sticky traps. Environmental Entomology 37, 79-86.

Nathan R. (2001) The challenges of studying dispersal. Trends in Ecology and Evolution 16, 481-483.

Nderitu J. H., Mwangi F., Nyamasyo G. N. and Kasina M. J. (2009) Evaluation of cropping systems as a strategy for managing snap bean flower thrips in Kenya. International Journal of Sustainable Crop Production 4, 22-25.

Nyasani J. O., Meyhöfer R., Subramanian S. and Poehling H.-M. (2012) Effect of intercrops on thrips species composition and population abundance on French beans in Kenya. Entomologia Experimentalis et Applicata 142, 236-246.

Nyasani J. O., Meyhöfer R., Subramanian S. and Poehling H.-M. (2013a) Feeding and oviposition preference of Frankliniella occidentalis for crops and weeds in Kenyan French bean fields. Journal of Applied Entomology 137, 204-213.

Nyasani J. O., Meyhöfer R., Subramanian S. and Poehling H.-M. (2013b) Seasonal abundance of western flower thrips and its natural enemies in different French bean agroecosystems in Kenya. Journal of Pest Science 86, 515-523.

Pasek J. E. (1988) Influence of wind and windbreaks on local dispersal of insects. Agriculture, Ecosystems and Environment 22-23, 539-554.

Pearsall A. I. (2002) Daily flight activity of the western flower thrips (Thysan., Thripidae) in nectarine orchards in British Columbia, Canada. Journal of 
Applied Entomology 126, 293-302. doi:10.1046/j.14390418.2002.00657.x.

Pearsall I. A. and Myers J. H. (2001) Spatial and temporal patterns of dispersal of western flower thrips (Thysanoptera: Thripidae) in nectarine orchards in British Columbia. Journal of Economic Entomology 94, 831843.

Rao J.S. (1967) Large sample tests for the homogeneity of angular data. Sankhya Series $B$ 28, 172174.

R Development Core Team (2010) R: A Language and Environment for Statistical Computing. R Foundation for Statistical Computing, Vienna, Austria. Available at: http:/ / www.R-project.org.

Reitz S. R. (2009) Biology and ecology of the western flower thrips (Thysanoptera: Thripidae): the making of a pest. Florida Entomologist 92, 7-13.

Rhainds M. and Shipp L. (2003) Dispersal of adult western flower thrips (Thysanoptera: Thripidae) on chrysanthemum plants: impact of feeding-induced senescence of inflorescences. Environmental Entomology 32, 1056-1065.

Rhainds M. and Shipp L. (2004) Dispersal of adult western flower thrips (Thysanoptera: Thripidae) in greenhouse crops. The Canadian Entomologist 136, 241-254.

Rhainds M., Shipp L., Woodrow L. and Anderson D. (2005) Density, dispersal, and feeding impact of western flower thrips (Thysanoptera: Thripidae) on flowering chrysanthemum at different spatial scales. Ecological Entomology 30, 96-104. doi:10.1111/j.03076946.2005.00663.x.

Ricklefs R. E. and Miller G. L. (2000) Ecology. 4th ed. W.H. Freeman Co. Ltd, New York. 833 pp.

Roslin T. (2000) Dung beetle movements at two spatial scales. Oikos 91, 323-335. doi:10.1034/j.16000706.2000.910213.x.

Wells N. A. (2000) Are there better alternatives to standard rose diagrams? Journal of Sedimentary Research 70, 37-46. doi: 10.1306/2DC408FC-0E47-11D78643000102C1865D. 